\title{
APOIO MATRICIAL DO NASF: UMA REVISÃO SISTEMÁTICA DE LITERATURA
}

\author{
MATRIX SUPPORT IN THE FAMILY HEALTH SUPPORT CENTER (NASF): SYSTEMATIC REVIEW \\ OF LITERATURE
}

APOYO MATRICIAL DEL NASF: REVISIÓN SISTEMÁTICA DE LITERATURA

\author{
Cristiane Belo de Araújo* \\ João Leite Ferreira Neto**
}

\begin{abstract}
RESUMO
Este trabalho de revisão de literatura tem o objetivo de verificar como o apoio matricial tem sido descrito, no âmbito nacional, por pesquisas empíricas que envolvem os Núcleos de Apoio a Saúde da Família (NASF) e as Equipes de Saúde da Família (EqSF). Processou-se a revisão sistemática de literatura com a busca de artigos na Biblioteca Virtual em Saúde/Brasil, entre outubro de 2016 e maio de 2017 . Foram selecionadas doze pesquisas, com data de publicação entre 2013 e 2017, que trabalharam com dados empíricos no conteúdo. Evidenciou-se um NASF cercado por muitos desafios e entraves, tais como o grande número de EqSF para referenciar; a dificuldade na integração com as equipes de referência; a fragilidade dos vínculos de trabalho; e a carência de recursos materiais e humanos. O que se pode concluir é que existem modos plurais de apoio matricial, transpondo o que está prescrito no plano conceitual.
\end{abstract}

Palavras-chave: NASF. EqSF. Apoio matricial. Revisão sistemática de literatura.

\section{ABSTRACT}

This paper consists of a literature review aiming to understand how matrix support is being described nationwide by empirical researches involving the Family Health Support Centers (NASF) and the Family Health Teams $(\mathrm{EqSF})$ - Acronyms in Portuguese. We carried out a systematic literature review, searching for articles in the Virtual Health Library/Brazil, between October 2016 and May 2017. Twelve researches published between 2013 and 2017 which dealt with empiric data within the content were selected.

\footnotetext{
Texto recebido em 10 de abril de 2016 e aprovado para publicação em 27 de outubro de 2017.

Este trabalho foi realizado com apoio da Coordenação de Aperfeiçoamento de Pessoal de Nível Superior - Brasil (Capes) - Código de Financiamento 001.

*Doutora em Psicologia pelo Programa de Pós-Graduação em Psicologia da Pontifícia Universidade Católica de Minas Gerais (PUC Minas) e psicóloga escolar/educacional na Universidade Federal de Alfenas (Unifal-MG). E-mail: crisbeloar@gmail.com.

"Professor adjunto IV do Programa de Pós-Graduação em Psicologia da PUC Minas e bolsista de produtividade do CNPq. E-mail: jleitefn@gmail.com.
} 
The evidences showed that the NASFs were surrounded by several challenges and obstacles, such as a large number of EqSFs to be referred to; the difficulty to interact with the reference teams; the fragility of work bonds; and the lack of human and material resources. What can be concluded is that there are plural ways of matrix support, transposing what is prescribed in the conceptual plane.

Keywords: NASF. EqSF. Matrix support. Systematic review of literature.

\section{RESUMEN}

Este trabajo de revisión de literatura tiene como objetivo verificar cómo el apoyo matricial ha sido descrito en el ámbito nacional, por investigaciones empíricas que involucran a los Núcleos de Apoyo a la Salud de la Familia (NASF) y los Equipos de Salud de la Familia (EqSF). Se realizó una revisión sistemática de literatura con la búsqueda de artículos en la Biblioteca Virtual en Salud/Brasil, entre octubre de 2016 y mayo de 2017. Fueron seleccionadas doce investigaciones, publicadas entre 2013 y 2017, que trabajaron con datos empíricos en el contenido. Se evidenció un NASF rodeado por muchos desafíos y obstáculos, tales como: el gran número de EqSF para referenciar; la dificultad de integración con los equipos de referencia; la fragilidad de los vínculos de trabajo y; la carencia de recursos materiales y humanos. Se concluye que existen modos plurales de apoyo matricial, transponiendo lo que está prescrito en el plano conceptual.

Palabras clave: NASF. EqSF. Apoyo matricial. Revisión sistemática de literatura. 


\section{INTRODUÇÃO}

Dara que haja a ampliação, o fortalecimento e a maior resolubilidade das ações na atenção básica, o apoio matricial deve ser incorporado pela equipe 1 do Núcleo de Apoio a Saúde da Família (NASF) e se constituir como uma prioridade do seu trabalho. Para tanto, faz-se necessário indagar e problematizar sobre o que está se tratando aqui como apoio matricial, uma definição conceitual originalmente cunhada por Campos (1999) e num contexto diverso e anterior à criação dos NASF.

No Cadernos de Atenção Básica, número 27 (Brasil, 2010), a noção de apoio matricial aparece articulada à de equipe de referência - uma discussão já apresentada por Campos (1999) - sendo esta percebida como um modo operante distinto do tradicional, em que, em vez de haver profissionais que se responsabilizam por procedimentos, há profissionais que se responsabilizam por pessoas. Nesse caso, em específico, a publicação ministerial traz o destaque de que, na atenção básica, ao falar em equipes de referência, está se referindo às equipes de saúde da família (EqSF), as quais se incubem de acompanhar um determinado contingente populacional em um dado recorte territorial.

Além de um deslocamento em termos do foco da responsabilidade do profissional (de procedimentos para pessoas), a equipe de referência também pressupõe a ideia de intercessões e de integração entre os diferentes saberes técnicos, levando à distribuição do poder e contrapondo-se, portanto, à tradicional fragmentação dos cuidados em saúde. E é dentro desse novo arranjo que se situa a discussão do apoio matricial, uma vez que ele deverá se dirigir a essas equipes de referências (Brasil, 2010).

O que o Ministério da Saúde (Brasil, 2010) apresenta em relação à retaguarda especializada está articulado ao que Campos (1999 apud Minozzo \& Costa, 2013) afirma sobre o fato de que o apoio matricial "configura-se como um suporte técnico especializado ofertado às equipes de APS, a fim de ampliar seu campo de atuação e qualificar suas ações, podendo ser realizado por profissionais de diversas áreas especializadas" (p. 151).

O Ministério da Saúde (Brasil, 2010) reconhece a existência de dois âmbitos em que o apoio matricial pode ser operacionalizado: o assistencial e o técnicopedagógico. Nota-se a inspiração que o texto governamental tem em relação ao que já havia sido proposto por Campos e Domitti (2007), quando também discutem sobre essas duas dimensões do apoio. Para os autores, a dimensão assistencial refere-se ao atendimento clínico, às ações de saúde destinadas à 
população. A técnico-pedagógica remete às ações educativas, de formação de conhecimento com e para a equipe que está sendo apoiada.

Ao considerar essas duas dimensões do apoio matricial, é possível entender o que, Campos et al. (2014) citado por Hirdes e Silva (2017), elencam como as suas principais contribuiçóes: pedagógica, institucional e terapêutica. Assim, mencionam mudanças que envolvem desde a melhoria do conhecimento, o que favorece a elevação da capacidade técnica dos profissionais, até as relações propriamente ditas.

Embora essa discussão trazida por Campos (1999) seja anterior ao NASF, observa-se acentuada proximidade com o que, mais tarde, o Ministério da Saúde (Brasil, 2010) apresenta quando trata do NASF, como equipe apoiadora, e da EqSF, como equipe de referência.

É importante mencionar que, em 21 de setembro de 2017, foi aprovada a Portaria no 2.436, que aprova a Política Nacional de Atenção Básica e estabelece a revisão de diretrizes para a organização da atenção básica. Desse momento em diante, houve uma mudança na nomenclatura do NASF, que, em vez da palavra "apoio", passou a apresentar o termo "ampliado", sendo, então, denominado como Núcleo Ampliado de Saúde da Família e Atenção Básica (NASF-AB). Portanto, de acordo com informação constante no site da atenção básica (Brasil, 2017), o núcleo terá uma ampliação do número de equipes para as quais se destina seu apoio. Assim, ele não apoiará apenas as EqSF, mas também as equipes de Atenção Básica (eAB). Dessa maneira, a perspectiva do apoio permanece, mas agora de maneira ampliada, contemplando equipes que, até então, não eram beneficiadas por ele. $\mathrm{Na}$ nova portaria, o apoio matricial aparece citado entre as estratégias de fortalecimento da atenção básica e como uma das atribuições dos seus profissionais.

Porém, considerando o período em que se procedeu a revisão sistemática da literatura, de outubro de 2016 a maio de 2017, e o contexto dos artigos analisados, os quais são anteriores à Portaria no 2.436 de 2017, julga-se coerente adotar, neste trabalho, a nomenclatura original do NASF como Núcleo de Apoio à Saúde da Família.

Assim, este artigo objetiva verificar como o apoio matricial tem sido descrito, no âmbito nacional, por pesquisas empíricas que envolvem os NASF e as EqSF. 


\section{MÉTODO}

Foi realizada a revisão sistemática da literatura a partir da busca de artigos na base de dados da Biblioteca Virtual em Saúde (BVS) Brasil. O processo de busca compreendeu o período de outubro de 2016 a maio de 2017. A escolha por essa base de dados se refere à sua relevância nacional na divulgação de informações em saúde pública.

Para a seleção dos artigos identificados, foram definidos os seguintes critérios de inclusão: a pertinência do artigo com o objeto de estudo desta pesquisa e a disponibilidade on-line do texto completo. Como critério de exclusão, estabeleceuse artigos que fossem resultados apenas de estudos teóricos/conceituais, sem a análise de dados empíricos.

A identificação dos artigos na biblioteca virtual foi desenvolvida de quatro maneiras, de acordo com o uso dos seguintes descritores: "apoio e NASF", "EqSF e NASF", "apoio e EqSF" e, finalmente, "NASF".

$\mathrm{Na}$ primeira busca, utilizando os descritores "apoio e NASF", foram identificados 106 artigos, estando estes armazenados em bases de dados internacionais (87), bases de dados especializadas (4) e nacionais (15).

Desse total de 106 artigos identificados na primeira busca, foi realizada a seleção de 12 , tendo como referência os critérios de inclusão e de exclusão previamente definidos.

Em seguida, foram realizadas as outras três buscas de artigos (usando-se os demais descritores: "EqSF e NASF", "apoio e EqSF" e "NASF"). Contudo nenhuma delas agregou novos artigos.

Com isso, foi possível selecionar artigos que cotejassem, no trabalho de campo, o uso de entrevistas, observações, entre outras estratégias de produção dos dados, com base no cotidiano, propriamente dito, de atuação dos NASF. Isso se justifica pela pretensão de verificar como o apoio matricial tem sido descrito, no território nacional, por pesquisas empíricas que envolvem os NASF e as EqSF.

Os artigos selecionados são oriundos do campo da Psicologia e de outras áreas de conhecimento, como Medicina, Farmácia, Enfermagem, entre outras. Além disso, o corpo de artigos contempla pesquisas realizadas nas diferentes regiões do País (Norte, Nordeste, Sudeste, Sul e Centro-Oeste), com data de publicação entre os anos de 2013 e de 2017.

A seguir, apresenta-se uma tabela que sintetiza os 12 artigos selecionados para a análise que será apresentada neste trabalho. 
Quadro 1 - Artigos selecionados na BVS Saúde

\begin{tabular}{|c|c|c|}
\hline Autor(es) e ano de publicação & $\begin{array}{c}\text { Área(s) de } \\
\text { concentração }\end{array}$ & Contexto de pesquisa \\
\hline Klein e D'Oliveira (2017) & Medicina & São Paulo-SP \\
\hline Oliveira et al. (2017) & Psicologia & $\begin{array}{l}\text { Municípios do Rio Grande do } \\
\text { Norte }\end{array}$ \\
\hline Nakamura e Leite (2016) & Farmácia & Município da Região Sul \\
\hline Martinez, Silva e Silva (2016) & $\begin{array}{c}\text { Educação Física e } \\
\text { Dança }\end{array}$ & Goiânia-GO \\
\hline $\begin{array}{c}\text { Macedo, Ximenes-Guimarães, } \\
\text { Coelho-Sampaio, Pereira-Morais e } \\
\text { Carneiro (2016) }\end{array}$ & $\begin{array}{l}\text { Fisioterapia, } \\
\text { Enfermagem, } \\
\text { Medicina e Serviço } \\
\text { Social }\end{array}$ & Fortaleza-CE \\
\hline Cela e Oliveira (2015) & Psicologia & $\begin{array}{c}\text { Seis municípios do Rio Grande do } \\
\text { Norte }\end{array}$ \\
\hline Sousa, Oliveira e Costa (2015) & Psicologia & $\begin{array}{l}\text { Dois municípios do Rio Grande do } \\
\text { Norte }\end{array}$ \\
\hline Perrella (2015) & Psicologia & $\begin{array}{l}\text { Município pequeno porte na } \\
\text { Bahia }\end{array}$ \\
\hline Moura e Luzio (2014) & Psicologia & Maringá-PR \\
\hline $\begin{array}{c}\text { Lancman, Gonçalves, Cordone e } \\
\text { Barros (2013) }\end{array}$ & $\begin{array}{l}\text { Fonoaudiologia, } \\
\text { Fisioterapia e } \\
\text { Terapia Ocupacional }\end{array}$ & São Paulo-SP \\
\hline Leite, Andrade e Bosi (2013) & $\begin{array}{l}\text { Psicologia e } \\
\text { Medicina }\end{array}$ & Juazeiro do Norte-CE \\
\hline Azevedo e Kind (2013) & Psicologia & Belo Horizonte-MG \\
\hline
\end{tabular}

Fonte: produzida pelos autores.

\section{O APOIO MATRICIAL: MODOS DE SE FAZER}

Todas as pesquisas analisadas são de natureza qualitativa, e a entrevista semiestruturada aparece como uma das ferramentas de produção de dados mais recorrente. O período de produção de dados está entre o intervalo de 2010 e 2014, como é, por exemplo, o caso das seguintes pesquisas: 2010-2011 (Cela \& Oliveira, 2015; Sousa, Oliveira, \& Costa, 2015); 2011-2012 (Lancman, Gonçalves, Cordone, \& Barros, 2013); 2012 (Nakamura \& Leite, 2016); 2012 2014 (Oliveira et al., 2017); e 2014 (Klein \& d'Oliveira, 2017).

Nesse sentido, pode-se constatar uma carência de estudos que possibilitam compreender os modos de construção do apoio matricial em anos mais recentes, ou seja, posteriores ao ano de 2014.

Na pesquisa de Klein e d'Oliveira (2017), localizada no Município de São Paulo, as pesquisadoras identificaram que as concepçôes de matriciamento correspondiam à troca de saberes, capacitação e supervisão. Contudo verificaram 
relatos que expressavam dificuldades relativas a essas trocas entre os profissionais. Como experiências bem-sucedidas, apareceram as situações de aprendizagens entre os diferentes profissionais, de modo que, por exemplo, no contato com a EqSF, os psicólogos seriam convocados a lidar melhor com questôes objetivas (alimentação, sono, doenças prevalentes, etc.), e a equipe referenciada, com questôes subjetivas. Apesar disso, verificou-se que muitos psicólogos falavam sobre o que ensinavam e pouco sobre o que aprendiam, indicando que o ensinar era uma função mais predominante no NASF e o aprender na EqSF.

Apesar de haver relatos de uma valorização de relações horizontais, houve a percepção, entre os entrevistados, de que essas trocas se manifestavam mais no interior do próprio núcleo do que com a EqSF. Além disso, identificaram-se entendimentos diferentes e divergentes quanto à concepção de matriciamento e, consequentemente, do que se deveria fazer como apoiador. Alguns entrevistados entendiam que não deveriam se ocupar das ações assistenciais, enquanto outros entendiam que sim (Klein \& d'Oliveira, 2017).

Klein e d'Oliveira (2017) identificaram o apoio matricial como espaço de discussão de caso e de atendimento compartilhado, evidenciando-se a tensão de quem deverá prestar a assistência específica ao caso. Portanto, nessa realidade de estudo, o atendimento individual aparece, para alguns profissionais, subvalorizado por se entender como ação não esperada para o apoiador. Disso resultou a ideia de cabo de força trazida pelas pesquisadoras, pois se instalava uma verdadeira tensão entre NASF e EqSF para se definir quem se responsabilizaria por um dado atendimento, sobretudo em se tratando de áreas carentes de cuidado assistencial, como a saúde mental.

$\mathrm{Na}$ pesquisa de Oliveira et al. (2017), que contemplou municípios do Rio Grande do Norte, verificou-se que a organização dos trabalhos do NASF propriamente dita se encontrava centrada nas EqSF de zonas rurais e urbanas dos municípios envolvidos. Porém, por serem muitas as unidades de saúde da família referenciadas, a presença dos profissionais do NASF acabava ocorrendo de modo espaçado, o que se percebeu como algo que repercutia na qualidade das relações entre esses profissionais e os das EqSF.

O acesso dos profissionais do NASF aos usuários ocorria por meio de encaminhamentos da rede de atenção, como enfermeiros, agentes comunitários de saúde e por demanda espontânea. Assim, verificou-se uma concentração das atividades nesses atendimentos em detrimento das ações de suporte às EqSF (Oliveira et al., 2017). Percebe-se, portanto, uma lógica de funcionamento distinta daquela indicada na leitura da pesquisa de Klein e d'Oliveira (2017), em que a centralidade das ações de apoio estava nas ações de discussão de caso/ 
supervisão e o atendimento específico era o grande ponto de tensão dessa relação, por não haver um consenso quanto ao fato de isso ser uma atribuição do núcleo.

É pertinente compreender a existência de outro modo de se fazer o apoio matricial em relação ao que se encontra proposto no modelo teórico que serve de referência às diretrizes do Sistema Único de Saúde (SUS). Dessa forma, diante das especificidades da realidade investigada, é possível que tais profissionais percebessem que o acolhimento àquelas demandas era um modo de oferecer suporte às EqSF. $\mathrm{O}$ conceito de apoio matricial precisa ser relativizado em razão do contexto em que as práticas se desenvolvem. Contudo é prudente considerar o que os pesquisadores afirmam sobre a distorção do núcleo, ao assumir o caráter de um ambulatório de clínicas especializadas, entendendo ser necessário mais investimentos no matriciamento e na referência às EqSF.

Quanto às articulações, verificou três formas:

1) articulação multiprofissional entre os profissionais do próprio NASF;

2) articulação dos NASF com as EqSF; e

3) articulação com outras políticas sociais.

Em relação à segunda forma, 20 profissionais afirmaram que ela ocorria, sendo decorrente de encaminhamentos e de atividades conjuntas entre as equipes (Oliveira et al., 2017).

Do total de 24 psicólogos entrevistados, 13 informaram a participação em capacitação com durações variadas, de dois dias ou de até uma semana. No entanto, embora fosse avaliada de maneira positiva a possibilidade de troca de experiências, também foi verbalizada a percepção de insuficiência desses momentos de formação, quando as discussões foram consideradas, por exemplo, como superficiais (Oliveira et al., 2017).

$\mathrm{Na}$ pesquisa de Nakamura e Leite (2016), situada em um Município da Região Sul do Brasil e com o foco nos processos de trabalho dos farmacêuticos do NASF, verificou-se que a implantação dos NASF no Município estudado se fez acompanhada de reuniōes periódicas para a organização dos trabalhos. Mas, uma vez implantados os núcleos, os profissionais que foram sendo inseridos nas equipes não tiveram mais acesso a capacitações regulares, apenas à participação em poucas reuniōes do núcleo. Nesses casos, os profissionais informaram o empenho individual e o conhecimento dos trabalhos em curso no serviço.

De acordo com Nakamura e Leite (2016), a dedicação dos profissionais pesquisados às atividades compartilhadas com as EqSF era pequena dentro do 
cronograma mensal de ações. Além disso, as pesquisadoras indicaram uma carência de conhecimento quanto aos trabalhos do NASF, tanto por sua própria equipe quanto pela saúde da família. $\mathrm{O}$ acesso aos usuários também foi identificado como algo que requeria revisão. Nessa realidade, os casos apresentavam acesso direto ao farmacêutico, sem que, necessariamente, estivessem previamente referenciados pelas EqSF. As pesquisadoras apontaram que a relação prévia estabelecida na dispensa dos medicamentos favorecia esse acesso direto. Outra questão se referia aos encaminhamentos diretos por outros profissionais da rede, sem que, portanto, o atendimento aos usuários fosse decorrente de açóes planejadas de matriciamento.

Nakamura e Leite (2016) demonstraram como o apoio matricial pode ser construído a partir de espaços informais de relacionamento entre os profissionais, como no que se refere àquelas discussóes fora dos espaços formais de reuniōes.

O trabalho de campo de Nakamura e Leite (2016) suscita reflexóes sobre o fato de que a potência dos trabalhos do NASF pode estar diretamente correlacionada à estruturação das EqSF. Desse modo, quanto mais estruturada está a atenção básica, mais coerente pode ser a atuação do profissional do NASF aos objetivos previstos para o núcleo. Nos centros de saúde não estruturados, a atuação do farmacêutico parecia resumida ao espaço da farmácia.

Em decorrência dos acessos diretos dos usuários aos profissionais do NASF, percebe-se que o núcleo acaba servindo de porta de entrada para muitos casos. Mesmo que se possa dizer que essa deturpação ainda contribua para alguma forma de apoio aos trabalhos da EqSF, a grande questão limitadora está no fato de que essa possível forma de apoio ocorre de maneira não planejada, sem atender a fluxos ou a qualquer possibilidade de uma construção prévia de projetos terapêuticos singulares que partam das discussões compartilhadas de casos.

É necessário mencionar que, de acordo com a Portaria no 2.488, de 2011, embora o NASF seja parte constitutiva da atenção básica, o acesso a ele não se dá de modo direto e livre, cabendo às equipes de atenção básica (nesse caso, às EqSF) regular ou gerenciar esse acesso.

Já na pesquisa de Martinez, Silva e Silva (2016), em Goiânia (Região Noroeste), verificou-se que o desenvolvimento da política de saúde no Município estudado ocorreu de modo tardio, quando comparado à realidade de outras cidades. Particularmente, no que tange a implantação do NASF, esta ocorreu da seguinte forma: 2009, aprovação do projeto; 2010, seleção e formação de profissionais e; 2011, início da atuação do núcleo. 
As pesquisadoras observaram que os processos de trabalho no NASF estavam relacionados à experiência formativa em que os profissionais participaram no decorrer da implantação dos núcleos. Identificou-se, inclusive, que alguns profissionais chegaram a desistir da atuação no núcleo por não haver identificação com o caráter dos trabalhos, exemplificando a situação de médicos que questionavam a centralidade das ações de apoio às equipes de referência e não daquelas relativas ao atendimento clínico. Outra potencialidade observada nesse contexto foi a contratação de profissionais efetivos, diminuindo a rotatividade.

Um dos desafios relatados por Martinez et al. (2016) se refere à quantidade de EqSF referenciadas pelos NASF estudados. Na pesquisa, é apresentada a fala de um dos gestores entrevistados, o qual pontuou que os NASF referenciavam entre 13 e 15 EqSF, de modo que isso prejudicaria o desenvolvimento "adequado" do apoio matricial. Contudo o entrevistado indicou que era preferível tal realidade a deixar alguma EqSF sem referência.

A carência de recursos materiais e humanos também foi apontada na pesquisa de Martinez et al. (2016), o que naquela realidade apareceu nas falas de alguns entrevistados (dois gestores) como fator de insegurança e até mesmo da própria capacidade de manutenção do NASF naquele Município.

Martinez et al. (2016) concluíram que,

De maneira geral, a proposta de trabalho do NASF tem provocado resistências em algumas equipes de ESF que indicam, entre outros elementos, um distanciamento da realidade de trabalho e uma dificuldade no trabalho interdisciplinar exigido pelo apoio matricial (p. 104).

As pesquisadoras trazem contribuições quanto à análise dos trabalhos do NASF ao indicarem resistências e algumas possibilidades à ação de apoio ante essas contingências.

Sobre a pesquisa de Macedo, Ximenes-Guimarães, Coelho-Sampaio, PereiraMorais e Carneiro (2016), realizada em dois NASF de Fortaleza, o primeiro elemento apontado se referiu à relação entre a formação profissional e o modelo de atuação requerido no NASF. Há falas que evidenciam, segundo os pesquisadores, formações centradas numa perspectiva biomédica, tecnicista e de atenção individual, as quais não mais respondem às novas diretrizes de atuação, sobretudo quando se trata do NASF, onde se espera uma prática interdisciplinar, por exemplo. Essa situação desafiadora se mostrou associada à maioria dos profissionais com mais tempo de conclusão da graduação. Na pesquisa, foram verificados profissionais variando entre 1 a 17 anos de formado. 
Quanto aos trabalhos desenvolvidos, os pesquisadores identificaram a ênfase à atenção individual. Para Macedo et al. (2016), esse fato poderia estar fundamentado nos desafios observados, como os problemas relatados de infraestrutura e de qualificação profissional condizente com as diretrizes definidas para o trabalho no NASF. Contudo, apesar do espaço inadequado das unidades de saúde, ponderou-se quanto à possibilidade de que as açóes coletivas pudessem ser desenvolvidas dentro de outros espaços do território. Além dessas limitações, também foi identificada a carência de recursos materiais, como a disponibilidade de carro, por exemplo, a sobrecarga de trabalho e a dificuldade na construção do vínculo com algumas EqSF.

Como formas de apoio, Macedo et al. (2016) também identificaram reuniōes com diferentes atores, as quais aconteciam a partir de agendamentos prévios ou de solicitações ao NASF. Os pesquisadores observaram o quanto essas reuniões ocupavam a agenda dos NASF, entendendo-as como resultado da preocupação dos profissionais em oferecer apoio às EqSF. Os entrevistados também mencionaram atividades de visitas domiciliares, apoio matricial na saúde mental e grupos temáticos.

$\mathrm{Na}$ pesquisa de Cela e Oliveira (2015), que envolveu seis municípios do Rio Grande do Norte, identificou-se a relevância dos encaminhamentos direcionados ao NASF pela EqSF, como forma de articulação entre as duas equipes. Diante disso, as pesquisadoras constataram resquícios de uma prática a que elas se referiram como uma "lógica tradicional no sistema de saúde" (p. 35), o que, então, contribui para a manutenção de relações ainda verticalizadas e demarcadas por uma comunicação deficitária. Ao analisar essas práticas, percebe-se que nem sempre as ações desenvolvidas partem de uma integração e corresponsabilização entre as duas equipes, desde a concepção até a execução, o que é problemático para a efetivação do apoio matricial.

Porém, apesar disso, Cela e Oliveira (2015) informaram a percepção, pelas falas de um dos entrevistados do NASF, de uma tentativa de aproximação das EqSF como estratégia de construção de outro modo de atuação. Mencionouse, por exemplo, a intenção de oferecer a retaguarda especializada. Inclusive as pesquisadoras se referiram a uma realidade diferenciada, de modo que, "no relato do Psicólogo 5, vemos o estímulo à participação da equipe SF em todos os momentos da ação" e, ainda, "buscando incentivar a participação da equipe SF na dianteira das açôes" (p. 35).

A partir do que é relatado por Cela e Oliveira (2015), é possível refletir sobre como a operacionalização do apoio matricial pode ser diversa dentro de um mesmo Estado, que dirá quando essa análise se amplia para o território nacional. 
Sousa, Oliveira e Costa (2015), ao estudarem dois municípios do Rio Grande do Norte, observaram a prevalência de atendimento de caráter ambulatorial, resultante de demandas provenientes da gestão municipal, da coordenação das equipes e da EqSF. Quanto ao processo de implantação dos núcleos, observou-se que esse se deu de maneira específica em cada um dos municípios acompanhados. No Município A, houve a composição de uma primeira equipe, a qual participou de momentos de treinamentos, do projeto municipal do NASF e de discussão de documentos governamentais. Contudo, após uma troca de governo, essa equipe foi dissolvida. Depois novas contratações ocorreram, e a equipe para atuar no núcleo foi nomeada de modo estanque. De forma diferente, a implantação no Município B se fez respaldada por treinamentos, fóruns de discussões e pactuação de ações mediante demandas das EqSF.

Porém a mudança no modo de operar dos NASF (até então exclusivamente ambulatorial) ocorreu a partir de mecanismos distintos: no Município A, por parte da gestão; e, no Município B, pela própria equipe. No Município B, foi observada a implantação de outras ações, com a redução de carga horária destinada aos atendimentos e uma maior dedicação às atividades coletivas. $\mathrm{Na}$ outra cidade, foi destinada $60 \%$ da carga horária total para atendimento, $25 \%$ para visitas domiciliares e 15\% para atividades coletivas (Sousa et al., 2015).

A leitura da pesquisa de Sousa et al. (2015) permite perceber os desafios que o atendimento ambulatorial dissociado das EqSF, reducionista e fragmentado pelos "especialismos", pode impor para que o NASF opere conforme as diretrizes pertinentes. Aliás, demonstram como as equipes podem ser cindidas entre especialistas e apoiadores.

$\mathrm{Na}$ experiência descrita por Perrella (2015), num Município de pequeno porte da Bahia, observou-se que o NASF estudado referenciava oito EqSF. O núcleo permaneceu por um período sem o profissional de Psicologia, uma vez que ele havia saído da equipe para atuar na função de coordenação do serviço. Porém a autora informou tratar-se de uma especialidade desejada tanto pelo núcleo quanto pela EqSF.

Quanto às reuniôes de matriciamento, observaram-se aspectos que indicavam a fragilidade da relação entre as equipes de referência e de apoio, uma vez que algumas das EqSF não levavam casos para discussão e certos profissionais também não compareciam (médicos e alguns agentes comunitários de saúde), além de problemas de comunicação. Esse quadro estava associado à descrença das EqSF em relação aos trabalhos do núcleo, sendo relatadas algumas falas de profissionais que mencionavam o fato de o NASF não ter sido resolutivo em algum caso discutido anteriormente ou sobre a percepção de que o NASF e as 
reunióes não funcionavam. Observou-se a dificuldade do núcleo e da EqSF em trabalhar de forma articulada (Perrella, 2015).

Na pesquisa de Moura e Luzio (2014), situada num NASF de Maringá, menciona-se que o processo de implantação do NASF naquela localidade foi permeado por estudo e diálogo, a partir de uma comissão de gestores da Secretaria Municipal de Saúde. De acordo com as pesquisadoras, a comissão permitiu refletir e tratar dos seguintes elementos: número de núcleos a serem criados, as categorias profissionais constituintes e as EqSF a serem referenciadas. Foram definidas, em média, nove EqSF para cada núcleo.

Como modos de apoio, Moura e Luzio (2014) observaram, por exemplo, a participação em reuniões das EqSF, as quais aconteciam semanalmente e contavam com a presença de três ou quatro profissionais do NASF. Para as pesquisadoras, esses espaços representaram oportunidades para a discussão de casos e construção dos projetos terapêuticos singulares, por exemplo. Além disso, foi mencionada a colaboração do NASF junto às EqSF em grupos temáticos de prevenção e de promoção da saúde.

No cenário analisado por Lancman, Gonçalves, Cordone e Barros (2013), dois NASF do Município de São Paulo, observou-se que as reunióes assumiram importante espaço e que elas ocupavam grande parte da rotina de trabalho dos profissionais. Segundo as pesquisadoras, isso representava o início do matriciamento e, à semelhança do que já foi observado nas pesquisas anteriores, nessas reuniōes com as EqSF, ocorriam a discussão de casos e a definição dos profissionais que referenciariam os casos. Também foram relatadas a carência de recursos materiais e resistências na pactuação de ações compartilhadas com o NASF.

Consonante ao que se passou em outros contextos, na pesquisa realizada em Belo Horizonte, por Azevedo e Kind (2013), observou-se a existência de profissionais com formação que antecedeu o surgimento do NASF e que indicava uma orientação clínica. A conclusão da graduação variou entre 1981 e 2006. Foram identificadas buscas de conhecimento sobre o campo das políticas de saúde pública a partir de iniciativas pessoais.

Com a existência de 44 equipes de NASF no Município, em apenas 9 tinhase a presença do psicólogo em sua constituição. Porém Ferreira Neto (2011), citado por Azevedo e Kind (2013), ressaltam que a cidade já havia incorporado, previamente, profissionais de Psicologia, ligados à saúde mental, nas unidades básicas com a oferta de apoio matricial às EqSF. 
O profissional mais prevalente era o de Fisioterapia, o que era um reflexo das origens do NASF no Município, o qual se estabeleceu como parte da política de reabilitação, quando ofereciam suporte às EqSF no que se refere a essa dimensão do cuidado (Azevedo, \& Kind, 2013).

Quanto aos trabalhos, Azevedo e Kind (2013) mencionaram o atendimento individual, o trabalho coletivo com grupos e as visitas domiciliares. "O trabalho se organiza, segundo as psicólogas entrevistadas, por meio de reuniões das equipes de NASF com as ESF, por matriciamento, de reuniōes entre os componentes da equipe do NASF e em ações de reabilitação junto aos usuários" (p. 527). Nas reuniōes mensais, as EqSF indicavam os casos que entendiam requerer a intervenção do NASF. A partir disso, as equipes avaliavam conjuntamente se, de fato, tratava-se de uma demanda a ser atendida pelo núcleo e as orientações necessárias eram conduzidas. Em reuniões futuras, eram discutidas as situações dos casos e avaliada a necessidade de novas intervençóes.

Dentro do NASF, ocorriam reuniōes semanais para a discussão dos casos em acompanhamento pelo núcleo e a avaliação de intervenções, como a realização de visitas domiciliares e de trabalhos coletivos. As visitas domiciliares, por exemplo, eram conduzidas por pelos menos dois profissionais do núcleo e um agente comunitário de saúde (ACS). Essas visitas, as quais podem ser percebidas como uma das formas de construção do apoio matricial, representavam uma grande demanda e, por isso, o retorno numa dada residência, geralmente, ocorria após um mês (Azevedo \& Kind, 2013).

De modo geral, a partir de todas as análises empreendidas, percebe-se que o percurso de construção do apoio matricial pode ser demarcado por certa tensão, com práticas/expectativas que ora se aproximam de uma atuação coletiva-compartilhada ora da atenção individual-assistencial-ambulatorial. Dessa maneira, nem sempre o apoio matricial tem conseguido contemplar e integrar as duas dimensōes do cuidado, podendo verificar-se que, em algumas realidades, há a ênfase na atuação coletiva-compartilhada enquanto em outras há a proeminência das açôes de atendimento individual. Essa realidade ainda se faz cercada, por muitas vezes, como indica a literatura, por dificuldades estruturais (carência de recursos materiais, por exemplo). Além disso, a integração entre as equipes do NASF e das EqSF, em alguns contextos apresentados, ainda não está plenamente estabelecida.

Essa tensão entre a dimensão técnico-pedagógica e a assistencial remete ao que Tesser (2017) trata quanto às "duas reduções comuns sobre as funções dos NASFs: seu centramento na prestação de cuidados especializados aos usuários ("assistencialismo") ou no suporte técnico-pedagógico às equipes de SF" (p. 
566). Assim, essa experiência de batalha que algumas pesquisas evidenciaram remete a esse processo de polarização ou de reducionismo da concepção de matriciamento.

\section{A ATUAÇÃO DO PSICÓLOGO NO APOIO MATRICIAL}

Na pesquisa de Oliveira et al. (2017), entre os profissionais de Psicologia, destacou-se a condução de atividades socioeducativas (palestras e grupos temáticos) e de visitas domiciliares, as quais decorriam de demandas da EqSF e eram realizadas com os agentes de saúde. A terceira atividade mais realizada foi o atendimento clínico ambulatorial, o que parecia, em parte, justificar-se pela fragilidade da atenção secundária. A quinta atividade mais informada foi a do planejamento, porém ocorrendo individualmente por alguns profissionais, em vez de resultar de construções compartilhadas e dialogadas.

$\mathrm{Na}$ realidade estudada por Perrella (2015), um Município do Sudoeste da Bahia, a pesquisadora identificou a expectativa que se tinha em relação ao trabalho do psicólogo, pelo menos por parte da EqSF, de que ele realizasse atendimentos individualizados. Concomitantemente, também se verificou a dificuldade do NASF, que era da modalidade 1, e da EqSF de atuarem de maneira integrada, prevalecendo o distanciamento entre os profissionais de campos de saberes distintos. E, assim, "Se algum usuário relatasse tristeza ou outro tipo de sofrimento, logo ele deveria ser encaminhado para o psicólogo. Nesse cenário, a escuta daquela pessoa tornava-se algo exclusivo e propriedade deste especialista" (p. 447). Portanto, a demanda ainda era concebida como domínio privado de certos campos de conhecimento, mesmo que outros profissionais pudessem trazer contribuições para o seu manejo.

Como dito antes, o NASF estudado por Perrella (2015) havia ficado, por cerca de um ano, sem o profissional de Psicologia, pois o que compunha a equipe tinha assumido um cargo de gestão. Nesse sentido, quando ocorreu a entrada de outro psicólogo, este se deparou com o que a autora se refere como demanda reprimida e com os desafios de uma organização do trabalho que orientada pela "lógica do consultismo" (p. 446).

Leite, Andrade e Bosi (2013), a partir do estudo de um NASF num Município da Região Sul do Ceará, puderam constatar, pela fala de um dos entrevistados, que o principal papel da Psicologia no NASF era entendido como a produção do apoio matricial em saúde mental, mediante as demandas identificadas nas unidades de saúde. Segundo o relato de um dos entrevistados "A atuação da Psicologia no NASF se pauta no apoio, na orientação e no suporte às demandas 
da ESF" (p. 1172). Além de o apoio matricial assumir esse caráter educativo, observou-se também a sua potencialidade como efeito terapêutico, podendo acolher, por exemplo, sentimentos de angústia e de frustração vivenciados no cotidiano dos ACS. As autoras também mencionaram o envolvimento do psicólogo em atividades como as visitas domiciliares (também com a parceria dos ACS) e a realização de grupos psicoeducativos com usuários. É possível dizer, mediante a discussão apresentada na pesquisa, que o ACS assumiu importante papel na articulação NASF-EqSF.

Apesar das vigorosas demandas da equipe multiprofissional e da comunidade, os psicólogos dos NASF lutam por afastar-se da clínica tradicional mediante atendimentos individuais circunstanciais, visto que é inviável atender centenas de pessoas semanalmente em cada unidade de saúde (Leite, Andrade, \& Bosi, 2013, p. 1176).

Mais uma vez, percebe-se a existência de expectativas sobre a atuação da Psicologia e de demandas relacionadas à prática clínica individual.

Por fim, Leite et al. (2013) ainda mencionaram outros desafios para o trabalho do psicólogo, referentes à sobrecarga de demandas, ao pouco tempo dedicado a cada EqSF, uma vez que cada núcleo do Município era responsável por cerca de nove EqSF, em média, e a consequente dificuldade de construir vínculos com a comunidade.

Em relação à atuação do psicólogo, Azevedo e Kind (2013) observaram a realização de atendimentos individuais (além de visitas domiciliares e trabalhos com grupos), mas que não configuravam psicoterapia, com o entendimento dos profissionais de que isso não seria adequado para se fazer no núcleo. Mas esse posicionamento indica ser reflexo do modo como se encontra estruturada a atenção básica no Município de Belo Horizonte, a qual conta com outros psicólogos, para além daqueles do NASF, como é o caso dos que compóem as equipes de saúde mental nas unidades básicas de saúde (UBS).

Aliás, Ferreira Neto (2011, apud Azevedo, \& Kind, 2013) contextualiza que, muito antes da criação do NASF, a cidade já contava com as equipes de saúde mental prestando suporte às EqSF. Percebe-se, por conseguinte, um histórico prévio de práticas psicológicas prestando o apoio matricial ante as demandas de saúde mental identificadas na atenção básica.

Dentro dessa configuração da atenção básica local, Azevedo e Kind (2013) verificaram que, quando havia a existência de demandas de psicoterapia ou de saúde mental, por exemplo, o usuário era encaminhado para a equipe de saúde mental das UBS ou para o Centro de Referência em Saúde Mental (Cersam). Isso evidencia que a existência de outros dispositivos de atenção à saúde, contando 
com a presença do psicólogo, combinado a um histórico de apoio matricial anterior ao próprio NASF, influencia significativamente no modo como a assistência à saúde é efetivada pelo núcleo. Além disso, o fato do atendimento clínico em saúde mental na atenção básica não se fazer uma exclusividade do núcleo, contribui para que, de alguma maneira, as demandas que chegam ao NASF sejam mais bem filtradas do que em outros municípios onde há uma carência de recursos assistenciais.

O apoio matricial, a partir da perspectiva da Psicologia, pôde ser vislumbrado mediante alguns desafios também indicados por Azevedo e Kind (2013), como o que diz respeito à relação inversamente proporcional expressa pelo pequeno número desses profissionais nas equipes do NASF e o grande número de EqSF referenciadas. Isso repercutia em atendimentos mais espaçados ou no não atendimento de algumas demandas. Além disso, observou-se a dificuldade dos profissionais em comparecer em todas as reunióes de matriciamento. Outro complicador, de modo semelhante ao verificado em outros municípios, foi a ausência de capacitações para os profissionais do NASF.

Em relação à atuação do psicólogo, de modo geral, é possível observar que esse profissional se vê em meio a tensões e a possibilidades na construção do apoio matricial. O que se constata é que a Psicologia vem aprendendo a fazer o apoio matricial em ato, processo esperado para um campo de saber que vem desbravando novos espaços de atuação.

\section{CONSIDERAÇÕES FINAIS}

O processo de implantação dos NASF traz implicações para o seu modo de operar. Infelizmente o processo de treinamento dos profissionais assim como a definição de fóruns e, ou, de comissões para orientar a implantação dos núcleos não foi algo comum para todos os contextos estudados. Depreende-se que há indicativos de que, muitas das vezes, o NASF se estabeleceu sem a preparação prévia de seus profissionais ou daqueles que atuam na rede de atenção, o que seria relevante ao considerar que parcela desses indivíduos pode ser proveniente de uma formação anterior à criação do serviço.

Evidenciou-se um NASF que ainda se faz cercado por muitos desafios e entraves, tais como o grande número de EqSF para referenciar; a dificuldade na integração com as equipes de referência; o desconhecimento pelas EqSF quanto ao NASF; a fragilidade dos vínculos de trabalho; e a carência de recursos materiais e humanos. 
O que se pode concluir é que existem modos plurais de apoio matricial, transpondo o que, a princípio, está previsto no plano conceitual. As realidades de trabalho são complexas e exigem, a todo o momento, certa flexibilidade, pois nem todas as questões vivenciadas no cotidiano são inteiramente atendidas pelo que está prescrito.

Com relação à situação da Psicologia, os relatos evidenciam que esse campo do saber tem experimentado o processo de afirmação de uma nova identidade, ao mesmo tempo em que tem de lidar com as possíveis expectativas do atendimento clínico tradicional. Mas, de fato, não se pode deixar de considerar um aspecto indicado pelas pesquisas: um NASF que ainda luta para encontrar seu lugar, construir sua identidade e se fortalecer na atenção básica de saúde. 


\section{REFERÊNCIAS}

Azevedo, N. S., \& Kind, L. (2013). Psicologia nos Núcleos de Apoio à Saúde da Família em Belo Horizonte. Psicologia: ciência e profissão, 33(3), 520-535. Recuperado a partir de http://dx.doi.org/10.1590/S141498932013000300002

Brasil. (2010). Ministério da Saúde. Departamento de Atenção Básica. Diretrizes do NASF: Núcleo de Apoio à Saúde da Família. Brasília: Ministério da Saúde. (Cadernos de Atenção Básica, 27). Recuperado a partir de http://bvsms.saude. gov.br/bvs/publicacoes/caderno_atencao_basica_diretrizes_nasf.pdf

Brasil. (2017). Ministério da Saúde. Atenção básica. Brasília: MS. Recuperado a partir de http://www.saude.gov.br/artigos/770-sistema-nacional-desaude/40315-atencao-basica

Campos, G. W. S. (1999). Equipes de referência e apoio especializado matricial: um ensaio sobre reorganização do trabalho em saúde. Ciência e Saúde Coletiva, 4 (2), 393-403. Recuperado a partir de http://dx.doi.org/10.1590/S141381231999000200013

Campos, G. W. S. \& Domitti, A. C. (2007). Apoio matricial e equipe de referência: uma metodologia para gestão do trabalho interdisciplinar em saúde. Caderno de Saúde Pública, 23(2), 399-407. Recuperado a partir de http:// dx.doi.org/10.1590/S0102-311X2007000200016.

Cela, M. \& Oliveira, I. F. (2015). O psicólogo no Núcleo de Apoio à Saúde da Família: articulação de saberes e ações. Estudos de Psicologia, 20(1), 31-39. Recuperado a partir de http://dx.doi.org/10.5935/1678-4669.20150005

Ferreira Neto, J. L. (2011). Psicologia, políticas públicas e o SUS. São Paulo: Escuta, Belo Horizonte: Fapemig.

Hirdes, A. \& Silva, M. K. R. (2017). Matrix support in mental health in Primary Health Care: Barriers and facilitating factors. Estudos de Psicologia, 34(4), 499-511. Recuperado a partir de https://doi.org/10.1590/198202752017000400006

Klein, A. P. \& d'Oliveira, A. F. P. L. (2017). O "cabo de força” da assistência: concepção e prática de psicólogos sobre o apoio matricial no Núcleo de Apoio à Saúde da Família. Cadernos de Saúde Pública, 33(1), 1-10. Recuperado a partir de http://dx.doi.org/10.1590/0102-311X00158815 
Lancman, S., Gonçalves, R. M. A., Cordone, N. G., \& Barros, J. O. (2013). Estudo do trabalho e do trabalhar no Núcleo de Apoio à Saúde da Família. Revista Saúde Pública, 47(5), 968-975. Recuperado a partir de http://dx.doi. org/10.1590/S0034-8910.2013047004770

Leite, D. C., Andrade, A. B., \& Bosi, M. L. M. (2013). A inserção da psicologia nos Núcleos de Apoio à Saúde da Família. Physis Revista de Saúde Coletiva, 23(4), 1167-1187. Recuperado a partir de http://dx.doi.org/10.1590/S010373312013000400008

Macedo, M. A. V., Ximenes-Guimarães, J. M., Coelho-Sampaio, J. J., PereiraMorais, A. P., \& Carneiro, C. (2016). Análise do processo de trabalho no Núcleo de Apoio à Saúde da Família em Município do Nordeste brasileiro. Revista Gerencia y Políticas de Salud, 15(30), 194-211. Recuperado a partir de http://dx.doi.org/10.11144/Javeriana.rgyps15-30.aptn

Martinez, J. F. N, Silva, M. S., \& Silva, A. M. (2016). O Núcleo de Apoio à Saúde da Família em Goiânia (GO): percepções dos profissionais e gestores. Saúde em Debate, 40(110), 95-106. Recuperado a partir de http://dx.doi. org/10.1590/0103-1104201611007

Minozzo, F. \& Costa, I. I. (2013). Apoio matricial em saúde mental entre CAPS e saúde da família: trilhando caminhos possíveis. Psico-USF, 18(1), 151-160. Recuperado a partir de http://www.scielo.br/pdf/pusf/v18n1/v18n1a16.pdf

Moura, R. H., \& Luzio, C. A. (2014). O apoio institucional como uma das faces da função apoio no Núcleo de Apoio à Saúde da família (NASF): para além das diretrizes. Interface: comunicação, saúde, educação, 18(1), 973-986. Recuperado a partir de http://dx.doi.org/10.1590/1807-57622013.0333

Nakamura, C. A. \& Leite, S. N. (2016). A construção do processo de trabalho no Núcleo de Apoio à Saúde da Família: a experiência dos farmacêuticos em um município do sul do Brasil. Ciência e saúde Coletiva, 21(5), 1565-1572. Recuperado a partir de http://dx.doi.org/10.1590/141381232015215.17412014

Oliveira, I. F., Amorim, K. M. O, Paiva, R. A., Oliveira, K. S. A., Nascimento, M. N. C., \& Araújo, R. L. (2017). Atuação dos psicólogos nos NASF: desafios e perspectivas na atenção básica. Temas em Psicologia, 25(1). Recuperado a partir de http://dx.doi.org/10.9788/TP2017.1-17Pt

Perrella, A. C. (2015). A experiência da psicologia no NASF: capturas, embates e invenções. Gerais: Revista Interinstitucional de Psicologia, 8(2), 443-452. 
Recuperado a partir de http://pepsic.bvsalud.org/pdf/gerais/v8n2/v8n2a12. pdf

Portaria no 2.436, de 21 de setembro de 2017. Aprova a Política Nacional de Atenção Básica, estabelecendo a revisão de diretrizes para a organização da Atenção Básica, no âmbito do Sistema Único de Saúde (SUS). Diário Oficial da União, Brasília. Recuperado a partir de http://bvsms.saude.gov.br/bvs/ saudelegis/gm/2017/prt2436_22_09_2017.html

Portaria no 2.488, de 21 de outubro de 2011. Aprova a Política Nacional de Atenção Básica, estabelecendo a revisão de diretrizes e normas para a organização da Atenção Básica, para a Estratégia Saúde da Família (ESF) e o Programa de Agentes Comunitários de Saúde (PACS). Brasília. Recuperado a partir de http://bvsms.saude.gov.br/bvs/saudelegis/gm/2011/prt2488_21_10_2011. html

Sousa, D., Oliveira, I. F., \& Costa, A. L. F. (2015). Entre o especialismo e o apoio: psicólogos no Núcleo de Apoio à Saúde da Família. Psicologia USP, 26(3), 474-483. Recuperado a partir de http://dx.doi.org/10.1590/0103656420140059

Tesser, C. D. (2017). Núcleos de Apoio à Saúde da Família, seus potenciais e entraves: uma interpretação a partir da atenção primária à saúde. Interface comunicação, saúde educação, 21(62), 565-578. Recuperado a partir de http:// dx.doi.org/10.1590/1807-57622015.0939 